\title{
Development of a successive targeting liposome with multi- ligand for efficient targeting gene delivery
}

\author{
Kun Ma1,2, Haijun Shen ${ }^{1}$, Song Shen ${ }^{1}$, Men Xie ${ }^{1}$, Chuanbin Mao ${ }^{2}$, Liyan Qiu${ }^{1}$, and Yi Jin ${ }^{1,}$ \\ ${ }^{1}$ Institute of Pharmaceutics, College of Pharmaceutical Sciences, Zhejiang University, Hangzhou, \\ China \\ ${ }^{2}$ Department of Chemistry and Biochemistry, University of Oklahoma, Stephenson Life Sciences \\ Research Center, Norman, OK, USA
}

\section{Abstract}

Background-A successful gene delivery system needs to breakthrough several barriers to allow efficient transgenic expression. In the present study, successive targeting liposomes (STL) were constructed by integrating various targeting groups into a nanoparticle to address this issue.

Methods-Polyethylenimine (PEI) 1800-triamcinolone acetonide (TA) with nuclear targeting capability was synthesized by a two-step reaction. Lactobionic acid was connected with cholesterol to obtain a compound of [(2-lactoylamido) ethylamino]formic acid cholesterol ester (CHEDLA) with hepatocyte-targeting capability. The liposome was modified with PEI 1800-TA and CHEDLA to prepare successive targeting liposome (STL). Its physicochemical properties and transfection efficiency were investigated both in vitro and in vivo.

Results-The diameter of STL was approximately $100 \mathrm{~nm}$ with $20 \mathrm{mV}$ of potential. The confocal microscopy observation and potential assay verified that lipid bilayer of STL was decorated with PEI 1800-TA. Cytotoxicity of STL was significantly lower than that of PEI 1800-

TA and PEI 25K. The transfection efficiency of 10\% CHEDLA STL in HepG2 cells was the higher than of the latter two with serum. Its transfection efficiency was greatly reduced with excessive free galactose, indicating that STL was absorbed via galactose receptor-mediated endocytosis. The in vivo study in mice showed that $10 \%$ CHEDLA STL had better transgenic expression in liver than the other carriers.

Conclusions-STL with multi-ligand was able to overcome the various barriers to target nucleus and special cells and present distinctive transgenic expression. Therefore, it has a great potential for gene therapy as a nonviral carrier.

\section{Keywords}

gene delivery; liposome; nonviral vector; polyethylenimine; target delivery

\section{Introduction}

For successful gene delivery, the gene carrier must efficiently enter the cells and subsequently pass through the intracellular space to the nucleus. In this respect, biological membranes such as the plasma membrane, the endosomal membrane and the nuclear membrane are significant barriers that must be overcome [1-3]. Poor access of plasmids DNA to the nucleus represents the major barrier to the success of nonviral gene therapy [4].

\footnotetext{
Copyright $@ 2011$ John Wiley \& Sons, Ltd.

*Correspondence to: Yi Jin, 388 Yuhangtang Road, Hangzhou 310058, China, jinyizju@ hotmail.com.
} 
Over the last two decades, several strategies have been developed to overcome this barrier [5], such as cell-penetrating peptides [6], glycosyl residues [7], glucocorticoid (GC) ligand [8], and so on. Using glucocorticoid ligand as nuclear localization signal (NLS) to enhance transgenic expression was an alternative strategy [9-13].

In a previous study, polycation was conjugated with various GCs to obtain steroid polymers $[14,15]$, and their physicochemical properties and transgenic activity were investigated. The results of those studies confirmed the enhancement of gene delivery by the use of steroid polymers. However, as a result of a lack of other ligands, they might not be able to breakthrough all barriers during gene delivery in vivo, including cell membrane and plasmic barrier.

Ligand coupled liposomes are recognized as a promising strategy for improving selective targeting to diseased tissues in vivo, leading to a reduction in toxicity and improved therapeutic outcomes. Asialoglycoprotein receptor-mediated targeting of pharmaceuticals to hepatocytes is a promising approach to achieve cell-specific delivery after systemic administration because of the physiological features of the liver. The liver has a high blood flow and molecules entering the systemic circulation can easily obtain access to cells through the discontinuous endothelium of the liver. Galactose has been most extensively studied with respect to targeting genes to liver parenchymal cells because galactose moiety can be specifically recognized by asialoglycoprotein receptors (ASGPR) on hepatocytes [16-21].

In the present study, galactose was conjugated with cholesterol to synthesize a compound of [(2-lactoylamido) ethylamino]formic acid cholesterol ester (CHEDLA), which could bind to ASGPR on the surface of hepatic parenchymal cells. Triamcinolone acetonide (TA) was conjugated with low molecular weight polyethylenimine (PEI) (PEI 1800) to synthesize TAPEI polymer with nuclear targeting capability. Then, TA-PEI was incorporated with lipid bilayer of liposome [22]. The liposome was modified with CHEDLA to obtain a successive targeting liposome (STL), which has a nuclear and cellular targeting group. Its physicochemical properties and transgenic activity were investigated systematically both in vitro and in vivo, aiming to achieve the optimal targeting gene delivery system.

\section{Materials and methods}

\section{Materials}

Soybean phosphatidylcholine (SPC), cholesterol (Chol), cholesteryl chloroformate, lactobionic acid, PEI (branched, 1.8 and $25 \mathrm{kDa}$ ), 2-iminothiolane (Traut's reagent), fluorescein isothiocyanate (FITC), ethidium bromide and 3-[4,5-dimethylthiazol-2-yl]-2,5diphenyltetrazolium bromide (MTT) were purchased from Sigma-Aldrich Chemical Co., Ltd (Milwaukee, WI, USA). Lissamine ${ }^{\mathrm{TM}}$ (Rhodamine B 1,2-dihexadecanoyl-sn-glycero-3phosphoethanolamine, triethylammonium salt) was purchased from Molecular Probes, Inc. (Invitrogen, Carlsbad, CA, USA). RPMI 1640, penicillin-streptomycin (10 $000 \mathrm{U} / \mathrm{ml}$ ) and trypsin-ethylenediaminetetraacetic acid (EDTA) (0.5\% trypsin, $5.3 \mathrm{mM}$ EDTA tetrasodium) were obtained from Gibco BRL (Gaithersberg, MD, USA). Fetal bovine serum (FBS) was purchased from Sijiqing Biologic Co., Ltd. (Hangzhou, China). Methanesulfonyl chloride was purchased from Shanghai Jiachen Chemical Co., Ltd (Shanghai, China). TA was kindly provided by Zhejiang Xianju Pharmaceutical Co., Ltd. (Hangzhou, China), and its purity was over 99\%. A Promega Luciferase Assay Kit containing luciferase cell culture lyses reagent and luciferase substrates was obtained from Promega (Madison, WI, USA). The BCA Protein Assay Kit and Hoechst 33342 were purchased from Beyotime Institute of Biotechnology (Jiangsu, China). The plasmids (pGL-3) were propagated in Escherichia coli DH5 $a$, isolated, and purified using Axyprep Plasmid DNA Maxiprep Kit (Axygene 
Biotechnology Limited, Hangzhou, China). The purity and concentration of DNA was determined by measuring ultraviolet absorbance at 260 and $280 \mathrm{~nm}$. All other chemicals were of analytical grade.

\section{Synthesis of TA-PEI conjugates}

The conjugation reaction was performed as reported previously with some modification [23]. First, triamcinolone acetonide mesylate was synthesized as a reactive intermediate in the preparation of TA-PEI. To a solution of triamcinolone acetonide $(869 \mathrm{mg}, 2 \mathrm{mmol})$ in anhydrous pyridine $(20 \mathrm{ml})$ at $0{ }^{\circ} \mathrm{C}$ under $\mathrm{N}_{2}, 275 \mu \mathrm{l}$ of methane-sulfonyl chloride $(2.4$ mmol, 1.2 equivalents) was added dropwise with stirring. After $1 \mathrm{~h}$ at $0{ }^{\circ} \mathrm{C}$, another 0.8 equivalents of methanesulfonyl chloride was added drop-wise. After a total reaction time of $5 \mathrm{~h}$ at $0{ }^{\circ} \mathrm{C}$, under $\mathrm{N}_{2}$, ice- $\mathrm{H}_{2} \mathrm{O}(20 \mathrm{ml})$ was added. The precipitate was filtered, washed with $\mathrm{H}_{2} \mathrm{O}$, and dried to give a crude mesylate as a colorless solid. ${ }^{1} \mathrm{H}-\mathrm{NMR}[500 \mathrm{MHz}$, dimethylsulfoxide (DMSO)-d 6 ]: 0.81 (s, C-19, $\mathrm{CH}_{3}$ ), 1.12 (s, C-25, $\mathrm{CH}_{3}$ ), 1.33 (s, C-26, $\left.\mathrm{CH}_{3}\right), 1.47$ (s, C-18, $\left.\mathrm{CH}_{3}\right), 3.29$ (s, $\left.-\mathrm{OSO}_{2} \mathrm{CH}_{3}\right), 6.00(\mathrm{~s}, \mathrm{C}-4, \mathrm{CH}), 6.22(\mathrm{~m}, \mathrm{C}-2, \mathrm{CH}), 7.28$ (d, $\mathrm{C}-1, \mathrm{CH})$.

Triamcinolone acetonide coupling to low molecular weight PEI (1.8 $\mathrm{kDa})$ was performed with 2 equivalents of 2-iminothiolane (Traut's reagent), and 2 equivalents of triamcinolone acetonide mesylate in anhydrous DMSO for $4 \mathrm{~h}$ at room temperature under continuous stirring. The reaction was quenched by the addition of an excess amount of cold ethyl acetate. The precipitated product was filtered and solubilized in water and dialysed for 2 days against pure water using dialysis membrane [molecular weight cut-off (MWCO) 1000] and then filtered through 0.45 -nm syringe-type filter to remove insoluble impurities. The product was obtained after freeze-drying, yielding white powder. ${ }^{1} \mathrm{H}-\mathrm{NMR}(500 \mathrm{MHz}$, $\mathrm{D}_{2} \mathrm{O}$ ): 0.78 (s, C-19, $\mathrm{CH}_{3}$ ), 1.08 (s, C-25, $\mathrm{CH}_{3}$ ), 1.36 (s, C-26, $\left.\mathrm{CH}_{3}\right), 1.45$ (s, C-18, $\mathrm{CH}_{3}$ ), $2.31 \sim 3.97$ (m, $\left.-\mathrm{NHCH}_{2} \mathrm{CH}_{2} \mathrm{NH}-\right), 6.13(\mathrm{~s}, \mathrm{C}-4, \mathrm{CH}), 6.32(\mathrm{~d}, \mathrm{C}-2, \mathrm{CH}), 7.42(\mathrm{~d}, \mathrm{C}-1, \mathrm{CH})$.

\section{Synthesis of CHEDLA}

Synthesis of lactobiono-1,5-lactone-Lactobionic acid (LA) was converted to lactobionic-1, 5-lactone by repeating evaporation from methanol and ethanol $(1 / 1, \mathrm{v} / \mathrm{v})$.

Synthesis of 2-(cholesteryloxycarbonylamino) ethylamine (CHE)-Cholesteryl chloroformate $(450 \mathrm{mg}, 1 \mathrm{mmol})$ solved in dichloromethane $(60 \mathrm{ml})$ was slowly added dropwise into a solution of ethylene diamine $(5840 \mathrm{mg}, 100 \mathrm{mmol})$ in dichloromethane at 0 ${ }^{\circ} \mathrm{C}$ with stirring. A 100 -fold molar excess of ethylene diamine was added to minimize the side reaction. The mixture was stirred for overnight at $0{ }^{\circ} \mathrm{C}$. The solvent was removed under vaccum and the residue was partitioned between water and dichloromethane. The organic layer was washed with water twice, and then anhydrous sodium sulfate was added to absorb water overnight. The solution was filtered and the solvent was removed under reduced pressure. CHE was obtained as a white powder.

\section{Synthesis of [(2-lactoylamido)ethylamino] formic acid cholesterol ester}

(CHEDLA)-Lactobionic-1,5-lactone in anhydrous DMSO was added dropwise to the CHE dichloromethane solution, and then five drops triethylamine were added. The mixture was refluxed at $50{ }^{\circ} \mathrm{C}$ for $36 \mathrm{~h}$. The dichloromethane was removed under vaccum and the residue was filtered to remove insoluble substance. The filtrate was added to a two-fold volume of pure water and dialysed for 2 day against pure water using dialysis membrane (MWCO 12 000) to remove DMSO and lactobionic-1,5-lactone. The dialysate was evaporated to dryness under reduced pressure. The crude product was purified by dichloromethane and ethanol $(1 / 1, v / v)$ and the insoluble substance was filtered. The solvent was removed under reduced pressure and the pale yellow powder was obtained. The product was solubilized in DMSO- 
$\mathrm{d}_{6}$ for $1 \mathrm{H}-\mathrm{NMR}$ and ${ }^{13} \mathrm{C}-\mathrm{NMR}$ analysis (500 MHz; Bruker, Ettlingen, Germany). To obviate the interference of solvent, DEPT $135^{\circ}{ }^{13} \mathrm{C}-\mathrm{NMR}$ was performed to help the analysis of its spectrum. ${ }^{1} \mathrm{H}-\mathrm{NMR}\left(500 \mathrm{MHz}, \mathrm{DMSO}_{-} \mathrm{d}_{6}\right.$ ): 0.65 (s, C-18, CH3), 0.83 (d, C-26, CH3), 0.84 (d, C-27, CH3), 0.89 (d, C-21, CH3), 0.96 (s, C-19, CH3); 3.05 (m, C-2"', CH2), 3.14 (m, C-3'", CH2), 4.30 (m, C-3, CH), 4.61 (d, C-2', CH), 4.43 (d, C-4', CH), 4.73 (d, C-1" $\left.{ }^{\prime \prime}, \mathrm{CH}\right)$, 5.12 (m, C-3', CH), 5.33 (m, C-6, CH), 7.01 (t, NH-2 $\left.{ }^{\prime \prime \prime}\right), 7.72$ (t, NH-3 $\left.{ }^{\prime \prime \prime}\right) ;{ }^{13} \mathrm{C}-\mathrm{NMR}(125$ MHz, DMSO-d $\left.{ }_{6}\right): 172.84, \mathrm{C}^{\prime}{ }^{\prime}, 155.99, \mathrm{C}-1^{\prime \prime \prime}, 140.03, \mathrm{C}-5,122.05, \mathrm{C}-6,104.81, \mathrm{C}-1^{\prime \prime}$, 83.13, C-4', 75.93, C-5", 73.48, C-3", 73.28, C-3, 72.30, C-2', 71.64, C-5', 71.37, C-2", 70.73, C-3', 68.46, C-4" ${ }^{\prime \prime}, 62.59$, C-6', 60.89, C-6", 56.39, C-14, 55.86, C-17, 49.75, C-9, 42.11, C-13, 40.49, C-2"', 39.71, C-3"', 39.43, C-16, 38.64, C-24, 38.53, C-4, 36.85, C-1, 36.31, C-10, 35.92, C-22, 35.44, C-20, 31.65, C-8, 31.59, C-7, 28.09, C-2, 28.01, C-12, 27.62, C-25, 24.10, C-15, 23.46, C-23, 22.88, C-27, 22.62, C-26, 20.82, C-11, 19.23, C-19, 18.79, C-21, 11.91, C-18; electrospray ionization-mass spectrometry (ESI-MS) (m/s): [M $+\mathrm{Na}]^{+}$835.5; IR (Nujol): $3327.3(\mathrm{OH}), 2930.3$ (CH, alkenes), 1699.2 (HNCOO), 1626.1 $(\mathrm{NH}), 1576.8(\mathrm{NH}), 1245$ (HNCOO), 891.4 (HNCOO). Figure 1 shows the synthetic scheme. (For the FTIR spectrum of LA, CHE and CHEDLA, see Supporting information, Figure S1; for the ${ }^{1} \mathrm{H}-\mathrm{NMR}$ spectrum of CC, CHE, CHEDLA, see Figure S2; For the the ${ }^{13} \mathrm{C}-\mathrm{NMR}$ spectrum and the DEPT $135^{\circ}$ spectrum of CHEDLA, see Figures S3 and S4; for the ESI-MS spectrum of CHEDLA, see Figure S5)

\section{FITC-labeling of TA-PEI}

For fluorescent labeling, TA-PEI $(10 \mathrm{mg})$ were reacted with FITC $(2 \mathrm{mg})$ in DMSO at room temperature and incubated for $24 \mathrm{~h}$ in the dark with stirring. Separation of unreacted FITC was by dialysis (MWCO 1000) against PBS (pH 7.4) for $48 \mathrm{~h}$ and then distilled water for 48 $\mathrm{h}$ until free FITC could not be detected by thin-layer chromatography (chloroform/methanol $=1 / 1, \mathrm{v} / \mathrm{v}$ ) [23]. The products was lyophilized and stored at $-20^{\circ} \mathrm{C}$ until further use.

\section{Preparation and characterization of STL}

STL was prepared using reverse phase evaporation method. Briefly, SPC, Chol and CHEDLA (SPC:Chol = 8:2, molar ratio) were dissolved in chloroform. TA-PEI at different molar ratios with SPC was dissolved in distilled water (chloroform: water $=2: 1$, volume ratio), followed by the addition of the former solution. The mixed liquor was sonicated for 5 min to form emulsion with a bath-type sonicator. The emulsion was vacuumed gradually to remove the oil phase by rotary evaporation. The resulting liposomal solution was sonicated for 2 min with a bath-type sonicator and was sequentially extruded through polycarbonate membranes (Whatman, Schleicher \& Schuell, Dassel, Germany) with pore sizes of $0.22 \mu \mathrm{m}$, and stored at $4{ }^{\circ} \mathrm{C}$.

STL/pDNA complexes were prepared by mixing STL and pDNA at various weight ratios with brief vortexing and incubated for $30 \mathrm{~min}$ before use. The complex formation between STL and pDNA was analyzed by agarose gel electrophoresis. The mean particle size and zeta potential of STL and STL/pDNA complexes were determined by laser diffraction spectrometry (Malvern Zetasizer 3000HS; Malvern Instruments, Malvern, UK). The morphological shapes of STL and STL/pDNA complexes were observed using transmission electron microscopy (TEM; JEM 1230, JEOL, Tokyo, Japan) by negative staining using $2 \%$ phosphotungstic acid.

For preparation of fluorescently-labeled liposomes, FITC-labeled TA-PEI instead of nonlabeled TA-PEI and rhodamine DHPE (Lissamine ${ }^{\mathrm{TM}}$ ) $(10 \mathrm{~mol} \%$ of total lipids) were added to prepare STL without sonication. Then the STL solution was dropped on a glass slide and cover slips were mounted. The fluorescence was examined with a confocal laser 
scanning microscope (FV1000-IX81; Olympus, Tokyo, Japan). Structures of STL complex are schematically shown in Figure 2.

\section{Cytotoxicity assay}

Cytotoxicity of TA-PEI and STL was assayed using MTT reagent. Briefly, HepG2, HEK 293 cells were cultured in RPMI 1640 with $10 \%$ FBS and $100 \mu \mathrm{g} / \mathrm{ml}$ streptomycin and penicillin at $37{ }^{\circ} \mathrm{C}$ in an incubator with a humidified atmosphere containing $5 \% \mathrm{CO}_{2}$. The cells were seeded at 5000 cells per well in 96-well plates (Corning Inc., Lowell, MA, USA). One day later, the cells were transfected with TA-PEI/pDNA and STL/pDNA complexes at various weight ratios. The PEI 1800 and $25 \mathrm{~K}$ complexes comprised the control, at a weight ratio of 5.3:1 and 1.33:1, respectively. The amount of pDNA was fixed at $0.2 \mu \mathrm{g} / \mathrm{well}$. The cells were incubated for another $24 \mathrm{~h}$ at $37^{\circ} \mathrm{C}$. Then the medium was replaced with $20 \mu \mathrm{l}$ of MTT $(5 \mathrm{mg} / \mathrm{ml})$ solutions and $180 \mu \mathrm{l}$ of fresh medium without serum and further incubated for $4 \mathrm{~h}$. Subsequently, the medium was removed and $100 \mu \mathrm{l}$ of DMSO was added. The absorbance at $570 \mathrm{~nm}$ was measured by using an enzyme-linked immunosorbent assay plate reader (Thermo Multiskan Spectrum; Thermo Fisher Scientific Inc., Waltham, MA, USA).

\section{In vitro transfection efficiency}

To investigate the transfection efficiency of STL, STL was prepared with a different SPC:TA-PEI weight ratio and percentage content of CHEDLA. HepG2 cells were collected and seeded in 24-well plate at a density of $1 \times 10^{5}$ cells per well, 1 day before gene transfer. Then, the cells were washed twice with PBS, and STL/pDNA complexes were added. The amount of pDNA was fixed at $2 \mu \mathrm{g} /$ well. After incubation for $6 \mathrm{~h}$ at $37{ }^{\circ} \mathrm{C}$ in the presence or absence of 10\% FBS, the cells were washed twice with PBS. Then, the fresh RMPI 1640 containing 10\% FBS was added and the cells were further incubated for $48 \mathrm{~h}$. For luciferase assay, the cells were washed with PBS, solubilized with $200 \mu 1$ of reporter lysis buffer for $30 \mathrm{~min}$, transferred into tubes and centrifuged at $22000 \mathrm{~g}$. for $5 \mathrm{~min}$. The relative light units (RLUs) were measured with a luminometer (Turner Designs Luminometer Model TD-20/20; Promega). The total protein was measured according to a BCA protein assay kit and luciferase activity was expressed as RLU/mg protein. Each transfection was performed in triplicate to ascertain the reproducibility.

To investigate whether the transfection efficiency of STL were inhibited by galactose, the competitive study was performed in the presence of galactose $(100 \mathrm{mM})$ as a ASGPR competitor in HepG2 cells. The cells were transfected by STL/pGL-3 lipoplex, and both the transfection solution and culture medium contained galactose to saturate ASGPR. The lipoplexes at their optimal weight ratio were incubated with cells for $4 \mathrm{~h}$ in the absence of $10 \%$ FBS. Then, the transfection solution was removed, and the cells were rinsed with PBS. Fresh medium with $10 \%$ FBS was added and the cells were then incubated for $24 \mathrm{~h}$ before assay [24]. Lipoplexes without galactose were added as a control.

\section{In vivo transfection efficiency}

Imprinting control region mice (weighing 18-22 g) were anesthetized with a peritoneal injection of $20 \%$ urethane $(1 \mathrm{~g} / \mathrm{kg})$. An incision was made in the abdomen, and the portal vein was exposed. $0 \%$ or $10 \%$ CHEDLA STL/pDNA lipoplex was prepared in 5\% dextrose, and PEI 25K and TA-PEI 1800 complex as control. Each complex in $200 \mu 1$ of 5\% dextrose was injected into the portal vein at a dose of $50 \mu \mathrm{g}$ pDNA/mouse, and the abdomen was sutured. Mice were sacrificed $24 \mathrm{~h}$ later by cervical dislocation. The liver and other organs were harvested [25]. Untreated mice were used as a negative control.

Cryofixation was performed by the immersion of tissues in Tissue-Tek OCT embedding medium (Sakura, Torrance, CA, USA) followed by freezing at $-80^{\circ} \mathrm{C}$. Frozen sections of 5 
$\mu \mathrm{m}$ thickness were prepared with a cryotome cryostat (CM 1900; Leica, Wetzlar, Germany). Sections were mounted on slides and analyzed by fluorescence microscopy. Single-cell suspensions were prepared by mechanical disruption. The cells were washed thrice and fixed in an $8 \%$ buffered paraformaldehyde for $30 \mathrm{~min}$ at room temperature, and then resuspended in PBS. The percentage of cells positive for enhanced green fluorescent protein (EGFP) was determined by flow cytometry (Becton-Dickinson Biosciences, Franklin Lakes, NJ, USA) by setting a gate according to the control and 10000 cells were evaluated in each experiment [26].

\section{Statistical analysis}

Statistical analysis was performed using one-way analysis of variance. $p<0.05$ was considered statistically significant.

\section{Results}

\section{Synthesis of TA-PEI conjugates and CHEDLA}

21-hydroxy group of TA is not required for its pharmacological activity. TA-21-mesylate was synthesized to conjugate on PEI [27,28]. Moreover TA has more powerful pharmacological activity and affinity with receptor binding sites [29], so that it might translocate into the nucleus more efficiently. The synthesis of CHEDLA followed the procedures as reported previously with some modification [30] (Figure 1). Lactobionic acid was converted to lactobionic lactone by dehydration [31] and then combined with an amino group on the CHE under triethylamine catalysis to yield galactosylated cholesterol. The novel compound is amphipathic and could incorporate with liposome to increase distribution in liver.

\section{Preparation and characterization of STL}

With respect to the glucocorticoid-based PEI derivatives, glucocorticoid as a hydrophobic group could incorporate with lipid bilayer and PEI as a hydrophilic polycation could concentrate pDNA to enhance the transfection efficiency of liposome. STL with various molar ratios of CHEDLA was prepared and their ability to bind pDNA was investigated by gel retardation assays, varying the weight ratio (Figure 3). The weight ratio of TA-PEI/ pDNA varied from 0.3-5.0, although the molar ratio of lipid/TA-PEI was fixed at 6:4. The results show that pDNA was retarded completely by STL at the weight ratio 0.5:1 (TA-PEI/ pDNA, W/W), and no significant differences were obtained by varying the molar ratio of lipid/CHEDLA. This means that the CHEDLA would not interfere with the complex formation between STL and pDNA.

Without pDNA, the size of STL was approximately $160 \mathrm{~nm}$ and the zeta potential was approximately $25 \mathrm{mV}$ (Figure 4). The positive change of the liposomal zeta potential confirmed the modification of liposomes with TA-PEI. The size increased and zeta potential became negative at a weight ratio of 0.3:1 (TA-PEI/pDNA), which indicated the incomplete compaction between STL and pDNA. With the increase of weight ratio, the size of STL reduced gradually to $100 \mathrm{~nm}$ at 3:1 (w/w, TA-PEI/pDNA), and the zeta potential of STL increased to $18 \mathrm{mV}$ at 2:1 (w/w, TA-PEI/pDNA) without obvious change, which indicated the formation of compacted complexes. Furthermore, the size and zeta potential of STL with or without the CHEDLA was not significantly different, which indicated that CHEDLA did not effect the size and zeta potential of STL. Formation of liposome and complex was examined by TEM (Figure 5). The STL with 5\% CHEDLA (i.e. molar percentage) was a spherical liposome with a bilayer structure. The complex of STL/pDNA at 4:1 (w/w, TAPEI/pDNA) had a well-formed spherical shape and a compacted structure. The size of both nanoparticles observed by TEM was consistent with the results of dynamic light scattering. 
To obtain direct evidence that TA-PEI incorporated with liposome, fluorescence-labeled TA-PEI and lipid was used to prepare STL. Under confocal microscopy, fluorescence signals of FITC (green) and rhodamine (red) were merged into yellow ones (Figure 6). This indicated that FITC-labeled TA-PEI was incorporated into rhodamine-labeled multi-lamellar liposomes to form STL. Modification of liposomes with TA-PEI was also confirmed by the determination of the zeta-potential of the liposomes, and the polycation-modified liposomes showed high positive charges, which was different from the original liposome with a negative potential.

\section{Cytotoxicity assay}

The cytotoxicity of the different complexes was assessed using the MTT assay in 293 and HepG2 cells (Figure 7). After $24 \mathrm{~h}$ of incubation with different complexes, the PEI 25K/ pDNA complex showed the highest toxicity in both cells, with less than a half of cells remaining at the commonly used concentration in transfection experiments. The PEI 1800/ pDNA complex had no obvious toxicities to both cells, with $80 \%$ of cells being alive. As the weight ratio of TA-PEI/pDNA increased, the TA-PEI/pDNA and STL/pDNA complexes showed increased cytotoxicity, although lower than PEI 25K. The TA-PEI/pDNA complex exhibited more cytotoxicity than the STL/pDNA complexes at all weight ratios, whereas no major different cytotoxicities were observed between STL/pDNA complexes with and without CHEDLA. The results show that, after being incorporated in the liposome, the toxicity of TA-PEI was diminished statistically, which indicated that a more extensive dosage range of STL for gene transfer could be chosen.

\section{In vitro transfection efficiency}

The efficiency of luciferase expression of HepG2 cells was tested when the STL composition or TA-PEI/pDNA ratio was varied. First, the transfection efficiency was examined to optimize the STL composition (Figure 8). The STL (SPC:Chol = 8:2, molar ratio) without CHEDLA was prepared at molar ratios of 9:1, 8:2, 7:3, 6:4, 5:5, 4:6 of lipid and TA-PEI. All the STL/pDNA complexes were prepared at ratio 3:1 of TA-PEI:pDNA (w/ w). The results show that with an increasing molar ratio of lipid and TA-PEI from 9:1 to 6:4, the luciferase expression of STL was increased drastically and the optimum transfection was observed at a molar ratio of 6:4. To exceed 6:4, the transgene expression was decreased slightly without further fluctuation. It was suggested that, with the increasing contents in STL, TA-PEI could contribute more to transfection efficiency. However, with the further increase of TA-PEI, more and more steroid polycation in the liposome preparation had no positive effect. Too much TA-PEI might cause cytotoxicity and negatively impact upon transgene expression.

To achieve the optimal formulation of STL for tranfection, STLs (lipid:TA-PEI, 6:4, molar ratio) with $0 \%, 5 \%, 10 \%, 15 \%$ CHEDLA (i.e. molar percentage) were tested for their ability to deliver luciferase plasmid into HepG2 cells at different weight ratios of TA-PEI/pDNA. Figure 9 demonstrates that, with the molar percentage of CHEDLA increasing, the expression of reporting gene increased statistically. Appropriate transfection efficiency was observed when the molar percentage of CHEDLA was $10 \%$ at 3:1 of TA-PEI:pDNA (w/w) which was four-fold higher than with $0 \%$ ones. However, a higher amount of CHEDLA was not associated with an increase in levels of gene expression when its amount was higher than $10 \%$. It was suggested that an excess galactose concentration would be sufficient to saturate ASGPR binding sich that transfection efficiency was inhibited in the presence of too much ligand. All STL with different amounts of CHEDLA had the highest luciferase expression at a weight ratio of 3:1 (TA-PEI:pDNA), which was much higher than that of PEI 1800.

Considering the results for the size and zeta potential of complexes, it is suggested that, at a weight ratio of 3:1, STL could condense pDNA completely to form compacted complexes 
with a strong positive charge on the surface, which facilitated the transfer of gene into negatively-charged cells. However, at high weight ratio, too strong an interaction between STL and DNA might prevent the release of the DNA from the complexes [32].

It is well known that the transgene expression of polyplexes can be suppressed in the presence of serum. Such a tendency is unfavorable if the carrier is to be used in vivo. Thus, the transfection efficiency following delivery by STL, TA-PEI and PEI 25K complexes in vitro was investigated in the presence or absence of 10\% FBS (Figure 10). As is apparent, PEI 25K and TA-PEI complexes showed a higher transfection efficiency in the absence of serum, although the effect was markedly suppressed in the presence of serum. The amount of luciferase expression in the presence of $10 \%$ serum was only $10 \%$ and $50 \%$ for PEI $25 \mathrm{~K}$ and TA-PEI complexes, respectively, in comparison with that in absence of serum. Gene transfer efficiency of nontargeted polyplexes is often decreased or diminished in the presence of serum, and the reason is considered to be a result of the binding of negativelycharged serum proteins to the polyplex, which reduces the electrostatic interaction of the polyplex with the targeting cell membrane. By contrast, the transfection efficiency of $0 \%$ and $10 \%$ CHEDLA STL complexes in the presence of $10 \%$ serum was $182 \%$ and $127 \%$ of that in its absence, respectively, which was much higher than that of PEI $25 \mathrm{~K}$ and TA-PEI complexes in the presence of $10 \%$ serum. This means that STL is resistant against serum and favorable for transfection in vivo. Interestingly, even the nontargeted STL with 0\% CHELDA showed slightly enhanced transfection efficiency. The reason for this currently remains unknown and requires additional investigation. Hydrophobic molecules similar to TA have been found to bind serum apolipoproteins, which may trigger low-density lipoprotein receptor-mediated uptake.

To further demonstrate the effect of ASGPR-mediated gene transfer, the competition assay was carried out by adding excess free galactose $(100 \mathrm{mM})$ into the STL/DNA complex. The results showed that the transfection efficiency of STL/pDNA complexes was greatly suppressed in the presence of galactose added excessively, indicating that STL/pDNA complexes were absorbed via receptor-mediated endocytosis (Figure 11). This meant that STL with CHEDLA could target specifically to hepatic parenchymal cells, and might gain efficiently transgenic expression in the liver.

\section{In vivo transfection efficiency}

It was expected that STL could breakthrough the different barriers in the process of gene delivery to accomplish efficient transgenic expression. STL/pDNA lipoplex without or with $10 \%$ CHEDLA was prepared and injected into mice via the portal vein to investigate their transgenic activity in vivo, and PEI 25K and TA-PEI complex were used as control.

After $24 \mathrm{~h}$, the liver and other organs were excised and the section was made, which was then observed under a fluorescence microscope. Their GFP expression in liver of mice is shown in Figure 12. The order of GFP expression was: 10\% CHEDLA STL >0\% CHEDLA STL > PEI 1800-TA > PEI 25K. Fluorescent colonies were not found in other organs (data not shown). To quantify their transfection in vivo, GFP expression was monitored by flow cytometry (Figure 13). The GFP positive expression rate in the liver, which 10\% CHEDLA STL mediated, was $42.81 \%$, and $0 \%$ CHEDLA STL was $29.3 \%$, PEI 1800-TA was $23.9 \%$, and PEI $25 \mathrm{~K}$ was $10.5 \%$. The result was consistent with the fluorescence image, and indicated that, after being modified with TA-PEI and CHEDLA, the transfection efficiency of liposome in vivo was improved significantly. STL with 10\% CHEDLA could target to liver cells, leading to the highest transgenic expression. The transgenic expression of $10 \%$ CHEDLA STL was 1.46-fold greater than that of STL without CHEDLA, 1.79-fold greater than that of TA-PEI, and 4.08-fold greater than that of PEI 25K. Therefore, this result 
demonstrates that STL could cause a significant increase of transgenic activity in vivo, and was more suitable for application in vivo.

\section{Discussion}

To achieve more efficient gene transfection, it is necessary to overcome a number of existing barriers in the process from administration through to gene expression. In the present study, STL, in which liposome was adorned with TA-PEI and CHEDLA, was newly established. First, hydrophobic TA as NLS was conjugated with PEI 1800 to generate a steroid polycation, as described in a previous study [23]. Then, lactobionic acid was connected with cholesterol to obtain a galactosylated ligand with amphipathic properties. During the synthesis of CHE, ethanediamine with an excess portion of 100-fold was added to avoid the side reaction. After the reaction ending, dichlormethane was utilized to extract the product, and $\mathrm{H}_{2} \mathrm{O}$ was utilized to remove the unreacted ethanediamine and its salt.

Utilizing its hydrophobic anchor group, this novel steroid polycation could incorporate with the lipid bilayer to modify liposomes with PEI. Liposomes were incorporated with CHEDLA to form STL with a liver targeting group. Therefore, in this vehicle, liposome as a carrier has favorable biocompatibility, with stability and low toxicity. The CHEDLAbearing galactose group could be specifically recognized by primary hepatocytes to enhance the endocytosis of STL. PEI could promote the escape of STL from the endosome to cytoplasm utilizing the 'proton sponge effect'. After binding to the glucocorticoid receptor, GC could translocate from the cytoplasm into the nucleus, taking along pDNA, resulting in an efficient transgenic expression. The exact mechanism of action remains to be determined because TA may also act in a positive way as an anti-inflammatory agent and enhance endosomal escape.

The present study showed that the diameter of STL was approximately $100 \mathrm{~nm}$. After complexing with pDNA, its size did not change obviously, and its zeta potential was approximately $20 \mathrm{mV}$, which would facilitate its absorption and internalization by the cells. The addition of approximately 10\% CHEDLA also did not affect the physicochemical properties of STL, presumably because the CHEDLA molecule is electroneutral and its dosage was relatively low. As far as the confocal image was observed, STL double-labeled by FITC and rhodamine emitted yellow fluorescence. This indicated that TA-PEI was associated with the lipid bilayer of liposome. The finding that the zeta positive potential of STL was different from the negative potential of common liposomes also verified the modification.

The results of the cytotoxicity assay show that the toxicity of STL decreased significantly compared to that of TA-PEI. We considered that the liposome part had a better compatibility with cells, which might neutralize some toxicities of TA-PEI. On the other hand, the positive charge of TA-PEI was shielded partially by the lipid bilayer, such that the cell damage caused by cationic polymer was weakened. The STL with or without CHEDLA showed similar cytotoxic activities after complexation with pDNA, which indicated that the presence of CHEDLA did not depress cell viability.

HepG2 cells are well-known models of parenchymal cells in the liver, which are rich in ASGPR on the cell surface. The expression of the luciferase gene with STL was investigated in HepG2 cells. The optimal transfection efficiency of STL was obtained with a composition of lipid and TA-PEI at a molar ratio of 6:4. With more TA-PEI, STL could not mediate better gene expression. This suggested that excess TA-PEI might raise the cytotoxicity of STL to influence its transgenic activity. Without serum, the transfection efficiency of STL was lower than that of TA-PEI at the tested weight ratio. However, the situation was 
reversed with $10 \%$ serum. This implied that STL might execute better gene delivery in vivo than TA-PEI polymer, although the exact mechanism remains unclear. 10\% CHEDLA STL displayed the best transgenic efficiency among all the examined carriers. However, after HepG2 cells were co-incubated with free galactose, transfection was inhibited drastically, which indicated STL's hepatocyte ASGPR targeting capability. In vivo transfection was performed by portal vein administration in mice. 10\% CHEDLA STL showed better transgenic activity in the liver than the other investigated carriers, which was consistent with the results obtained in vitro. This indicated that STL could integrate various targeting groups into a nanoparticle, and these groups could execute their function synergistically to carry out efficient gene delivery.

In conclusion, we have shown the efficient targeting of a delivery gene into hepatocyte cells or tissue by means of STL modified with liver cell- and nucleus-specific ligands.

Optimization of the composition of STL improved its gene transfer efficiency both in vitro and in vivo, and with low toxicity. The multi-ligands could incorporate with liposome systematically to contribute to the excellent transfection efficiency. In addition, TA is a versatile pharmacological drug and comprises an effective anti-inflammatory, antirheumarthritis and anti-anaphylaxis reagent. Thus, STL may have synergistic effects (e.g. enhanced transfection and anti-inflammatory, anti-rheumarthritis, anti-anaphylaxis effects). The present study reports the successful attempt to construct a multi-functional nonviral gene delivery system. The detailed mechanism remains to be analyzed in future studies.

\section{Supplementary Material}

Refer to Web version on PubMed Central for supplementary material.

\section{Acknowledgments}

This work was supported by the grants from the National Natural Science Foundation of China (NSFC: 30873175 , 30973647), Zhejiang Provincial Natural Science Foundation of China (ZJNSF, Y2090229) and National Basic Research Program of China (973 Program, 2009CB930300).

\section{References}

1. van der Aa MA, Mastrobattista E, Oosting RS, Hennink WE, Koning GA, Crommelin DJ. The nuclear pore complex: the gateway to successful nonviral gene delivery. Pharm Res. 2006; 23:447459. [PubMed: 16525863]

2. Nishikawa M, Huang L. Non-viral vectors in the new millennium: delivery barriers in gene transfer. Hum Gene Ther. 2001; 12:861-870. [PubMed: 11387052]

3. Akita H, Kudo A, Minoura A, Yamaguti M, et al. Multi-layered nanoparticles for penetrating the endosome and nuclear membrane via a step-wise membrane fusion process. Biomaterials. 2009; 30:2940-2949. [PubMed: 19261326]

4. Brunner S, Sauer T, Carotta S, Cotten M, Saltik M, Wagner E. Cell cycle dependence of gene transfer by lipoplex, polyplex and recombinant adenovirus. Gene Ther. 2000; 7:401-407. [PubMed: 10694822]

5. Pouton CW, Wagstaff KM, Roth DM, Moseley GW, Jans DA. Targeted delivery to the nucleus. Adv Drug Deliv Rev. 2007; 59:698-717. [PubMed: 17681634]

6. Futaki S, Nakase I, Suzuki T, Zhang Yj, Sugiur Y. Translocation of branched-chain arginine peptides through cell membranes: flexibility in the spatial disposition of positive charges in membrane-permeable peptides. Biochemistry. 2002; 41:7925-7930. [PubMed: 12069581]

7. Arima H, Chihara Y, Arizono M, et al. Enhancement of gene transfer activity mediated by mannosylated dendrimer/a-cyclodextrin conjugate (generation 3, G3). J Control Release. 2006; 116:64-74. [PubMed: 17083992] 
8. Rebuffat A, Bernasconi A, Ceppi M, et al. Selective enhancement of gene transfer by steroidmediated gene delivery. Nat Biotechnol. 2001; 19:1155-1161. [PubMed: 11731785]

9. Braun S, Jenny $C$, Thioudellet $C$, et al. In vitro and in vivo effects of gluco-corticoids on gene transfer to skeletal muscle. FEBS Lett. 1999; 454:277-282. [PubMed: 10431822]

10. Rebuffat AG, Nawrocki AR, Nielsen PE, et al. Gene delivery by a steroid-peptide nucleic acid conjugate. FASEB J. 2002; 16:1426-1428. [PubMed: 12205036]

11. Gruneich JA, Price A, Zhu J, Diamond SL. Cationic corticosteroid for nonviral gene delivery. Gene Ther. 2004; 11:668-674. [PubMed: 14724671]

12. Choi JS, Ko KS, Park JS, Kim YH, Kim SW, Lee M. Dexamethasone conjugated poly (amidoamine) dendrimer as a gene carrier for efficient nuclear translocation. Int J Pharm. 2006; 320:171-178. [PubMed: 16769187]

13. Mi Bae Y, Choi H, Lee S, et al. Dexamethasone-conjugated low molecular weight polyethylenimine as a nucleus-targeting lipopolymer gene carrier. Bioconjug Chem. 2007; 18:2029-2036. [PubMed: 17850108]

14. Ma K, Hu M, Qi Y, et al. PAMAM-triamcinolone acetonide conjugate as a nucleus-targeting gene carrier for enhanced transfer activity. Biomaterials. 2009; 30:6109-6118. [PubMed: 19656564]

15. Ma K, Hu M, Qi Y, et al. Structure-transfection activity relationships with glucocorticoidpolyethylenimine conjugate nuclear gene delivery systems. Biomaterials. 2009; 30:3780-3789. [PubMed: 19375793]

16. Kim TH, Park IK, Nah JW, Choi YJ, Cho CS. Galactosylated chitosan/DNA nanoparticles prepared using water-soluble chitosan as a gene carrier. Biomaterials. 2004; 25:3783-3792. [PubMed: 15020154]

17. Fumoto S, Kawakami S, Ito Y, Shigeta K, Yamashita F, Hashida M. Enhanced hepatocyteselective in vivo gene expression by stabilized galactosylated liposome/plasmid DNA complex using sodium chloride for complex formation. Mol Ther. 2004; 10:719-729. [PubMed: 15451456]

18. Kim TH, Kim SI, Akaike T, Cho CS. Synergistic effect of poly(ethylenimine) on the transfection efficiency of galactosylated chitosan/DNA complexes. J Control Release. 2005; 105:354-366. [PubMed: 15949861]

19. Zhang XQ, Wang XL, Zhang PC, et al. Galactosylated ternary DNA/polyphosphoramidate nanoparticles mediate high gene transfection efficiency in hepatocytes. J Control Release. 2005; 102:749-763. [PubMed: 15681095]

20. Shigeta K, Kawakami S, Higuchi Y, et al. Novel histidine-conjugated galactosylated cationic liposomes for efficient hepatocyte-selective gene transfer in human hepatoma HepG2 cells. J Control Release. 2007; 118:262-270. [PubMed: 17267065]

21. Park IK, Kim TH, Park YH, et al. Galactosylated chitosan-graft-poly(ethylene glycol) as hepatocyte-targeting DNA carrier. J Control Release. 2001; 76:349-362. [PubMed: 11578748]

22. Köster F, Schröder A, Finas D, Hauser C, Diedrich K, Felberbaum R. Cell-specific enhancement of liposomal transfection by steroids in steroid receptor expressing cells. Int J Mol Med. 2006; 18:1201-1205. [PubMed: 17089027]

23. Ma K, Hu M-X, Xie M, et al. Investigation of Polyethylenimine-grafted-triamcinolone acetonide as nucleus-targeting gene delivery systems. J Gene Med. 2010; 12:669-680. [PubMed: 20635325]

24. Kim TH, Park IK, Nah JW, Choi YJ, Cho CS. Galactosylated chitosan/DNA nanoparticles prepared using water-soluble chitosan as a gene carrier. Biomaterials. 2004; 25:3783-3792. [PubMed: 15020154]

25. Yamazaki Y, Nango M, Matsuura M, Hasegawa Y, Hasegawa M, Oku N. Polycation liposomes, a novel nonviral gene transfer system, constructed from cetylated polyethylenimine. Gene Ther. 2000; 7:1148-1155. [PubMed: 10918482]

26. Morimoto K, Nishikawa M, Kawakami S, et al. Molecular weight-dependent gene transfection activity of unmodified and galactosylated polyethyleneimine on hepatoma cells and mouse liver. Mol Ther. 2003; 7:254-261. [PubMed: 12597914]

27. Dunkerton LV, Markland FS, Li MP. Affinity-Labelling Corticoids I. Synthesis of 21chloroprogesterone, deoxycorticosterone 21-(1-imidazole) carboxylate, 21-deoxy-21-chloro dexamethasone, and dexamethasone 21-mesylate, 21-bromoacetate, and 21-iodoacetate. Steroids. $1982 ; 39: 2828$. 
28. Simmons SS, Pons M, Johnson DF. $a$-Keto mesylate: a reactive, thiol-specific functional group. J Org Chem. 1980; 45:3084-3088.

29. Dahlberg E, Thalén A, Brattsand R, et al. Correlation between chemical structure, receptor binding, and biological activity of some novel, highly active, 16a, 17a-acetal-substituted glucocorticoids. Mol Pharmacol. 1983; 25:70-78. [PubMed: 6708937]

30. Yu FB, Jiang TY, Zhang JH, Cheng LH, Wang SL. Galactosylated liposomes as oligodexynucleotides carrier for hepatocyte-selective targeting. Pharmazie. 2007; 62:528-533. [PubMed: 17718195]

31. Willams TJ, Plessas NR, Goldstein IJ. Synthsis of a new class of model glycolipids. Carbohydrate Res. 1978; 67:C1-C3.

32. De Smedt SC, Remaut K, Lucas B, Braeckmans K, Sanders NN, Demeester J. Studying biophysical barriers to DNA delivery by advanced light microscopy. Adv Drug Deliv Rev. 2005; 57:191-210. [PubMed: 15518929] 

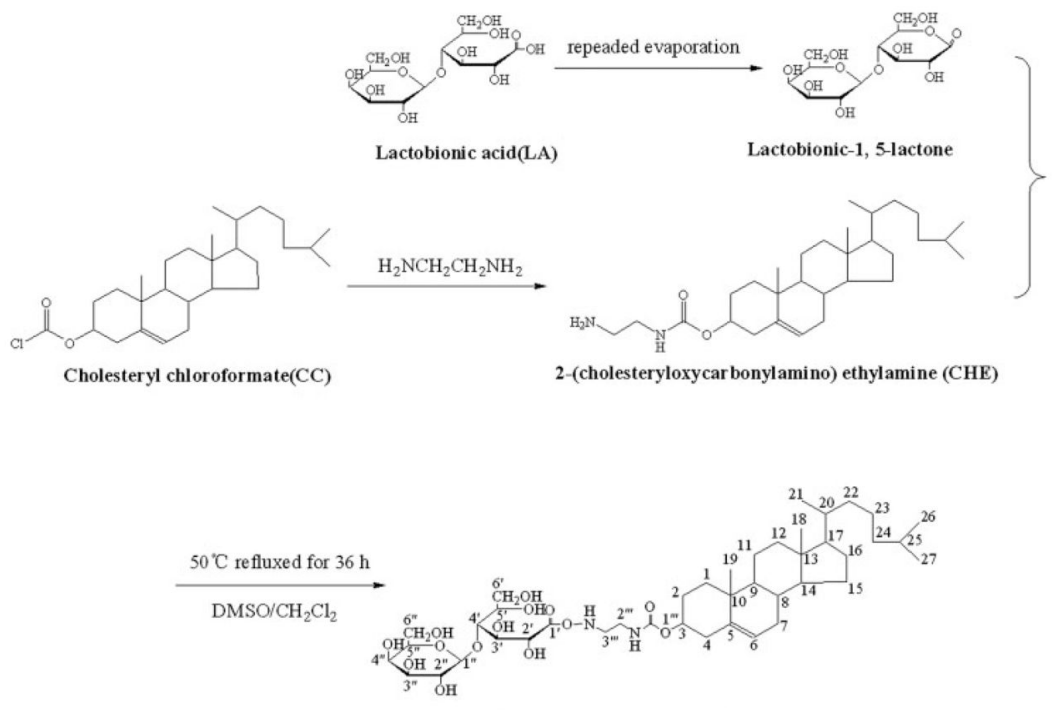

[(2-lactoylamido) ethylamino] formic acid cholester ol ester (CHEDLA)

Figure 1.

Scheme of synthesis of CHEDLA 


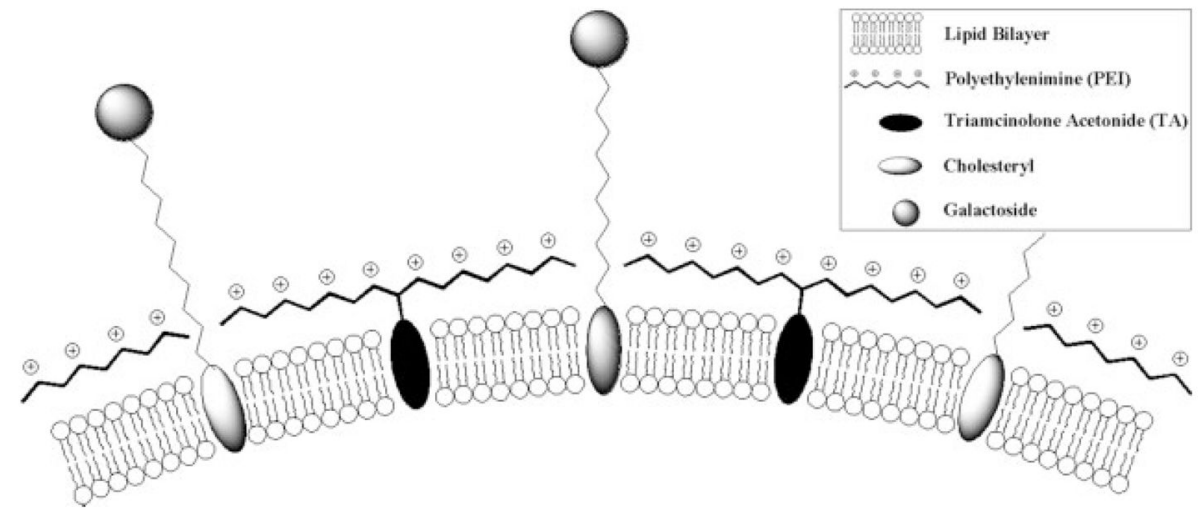

Figure 2.

Scheme of STL 
$\mathrm{TA}-\mathrm{PEI} / \mathrm{pDNA}(\mu \mathrm{g} / \mu \mathrm{g})$
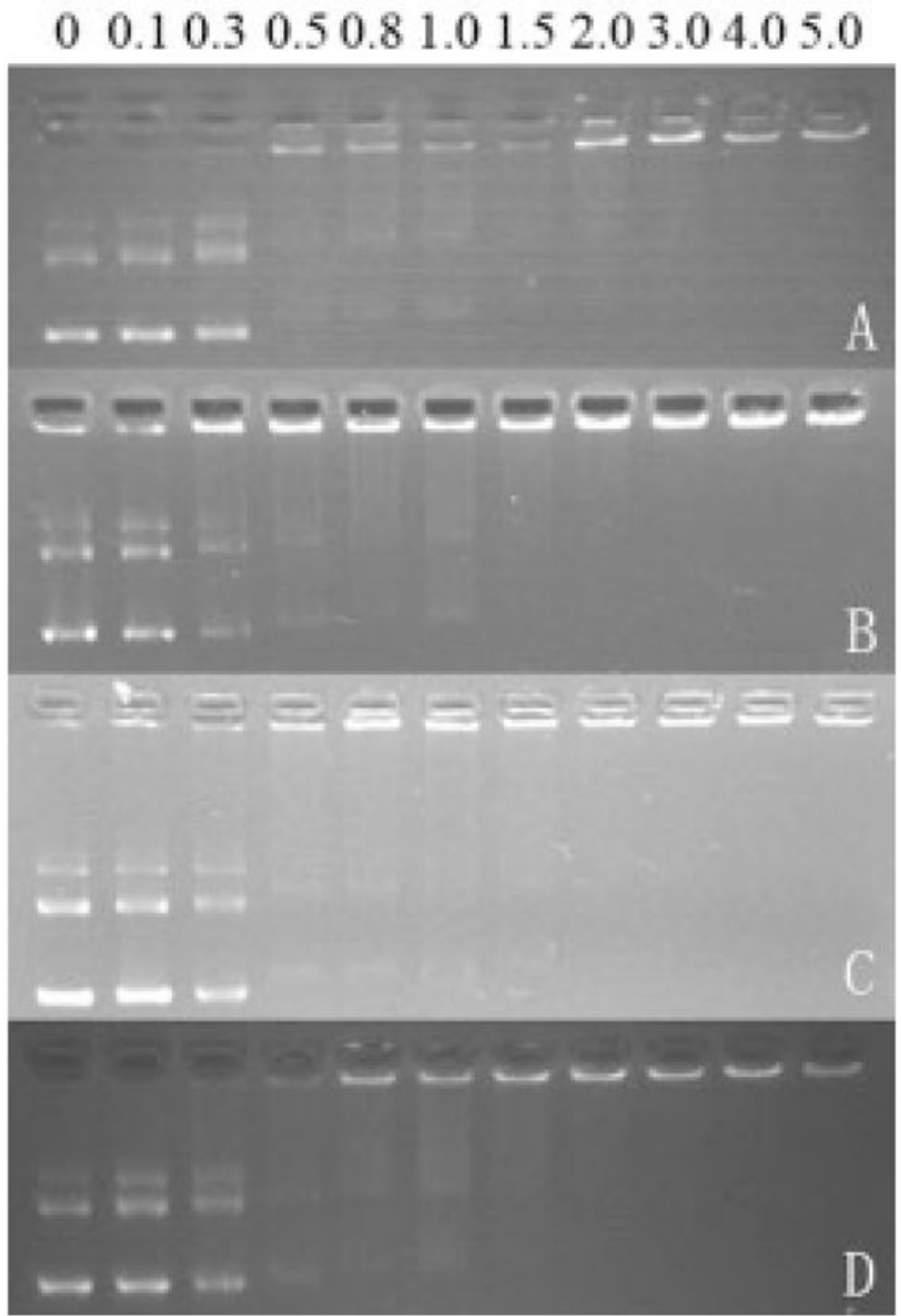

Figure 3.

Gel electrophoresis of the STL/DNA complex with varying TA-PEI/pDNA weight ratios from 0.3-5.0. The molar ratio of phospholipid/TA-PEI was fixed at 6:4. The STL was prepared with various molar percentage of CHEDLA (A, 0\%; B, 5\%; C, 10\%; D, 15\%). The mixtures were incubated at room temperature for $30 \mathrm{~min}$ and electrophoresis on $1 \%(\mathrm{w} / \mathrm{v})$ agarose gel and stained with ethidium bromide 

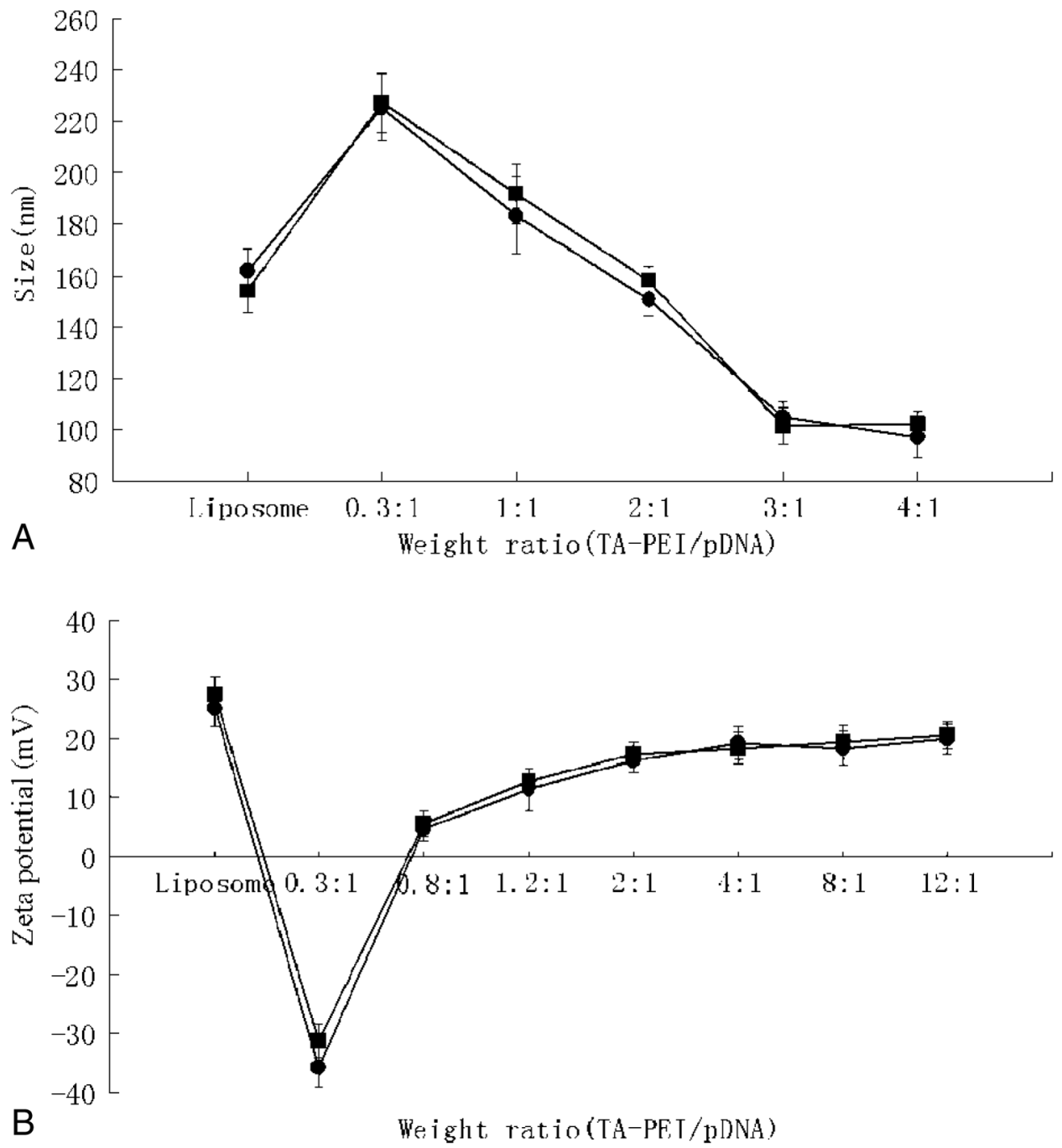

Figure 4.

Particle size (A) and zeta potential (B) of the STL/pDNA complexes (, $0 \%$ CHEDLA; $\mathbf{\square}$, $10 \%$ CHEDLA, molar percentage) at various TA-PEI/pDNA (w/w) ratios. The data represent the mean $\pm \mathrm{SD}$ of three experiments 

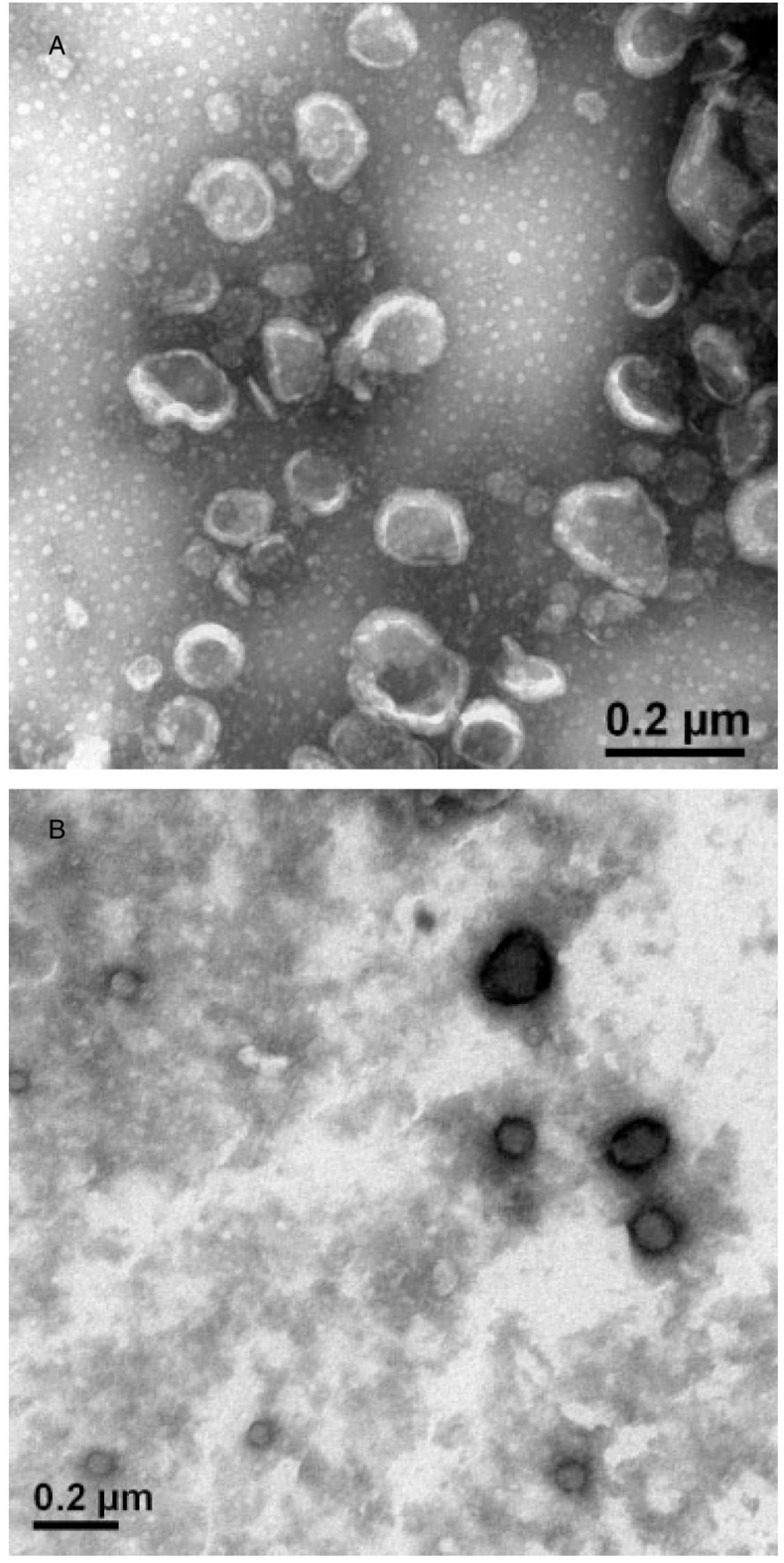

Figure 5.

TEM of STL (A) and STL/pDNA complex (B) at a weight ratio (TA-PEI/pDNA) of 3.

Complexes were negatively stained by $2 \%$ aqueous solution phosphotungstic acid for $30 \mathrm{~s}$. Scale bar $=200 \mathrm{~nm}$ 


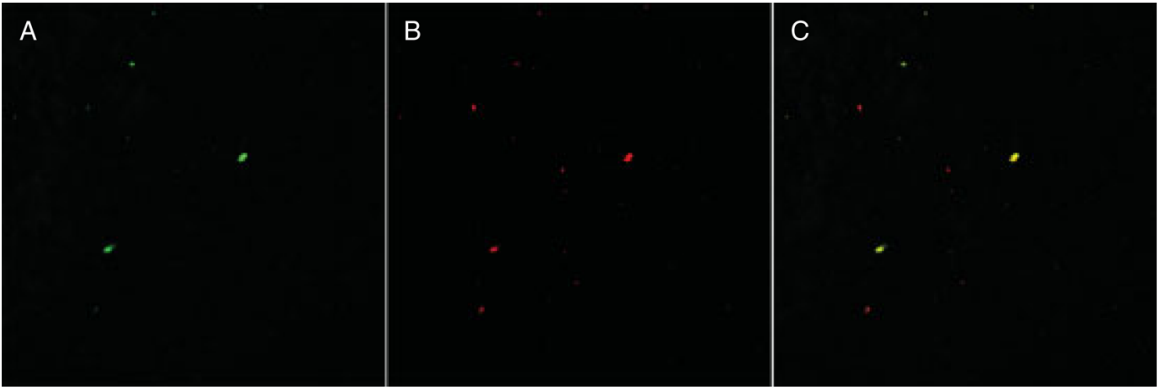

Figure 6.

CLSM of STL prepared with FITC-labeled PEI 1800-TA and Lissamine ${ }^{\mathrm{TM}}$. (A) FITC-PEI 1800-TA (green); (B) Lissamine ${ }^{\mathrm{TM}}$ (red); (C) merged images of (A) and (B) (yellow) 

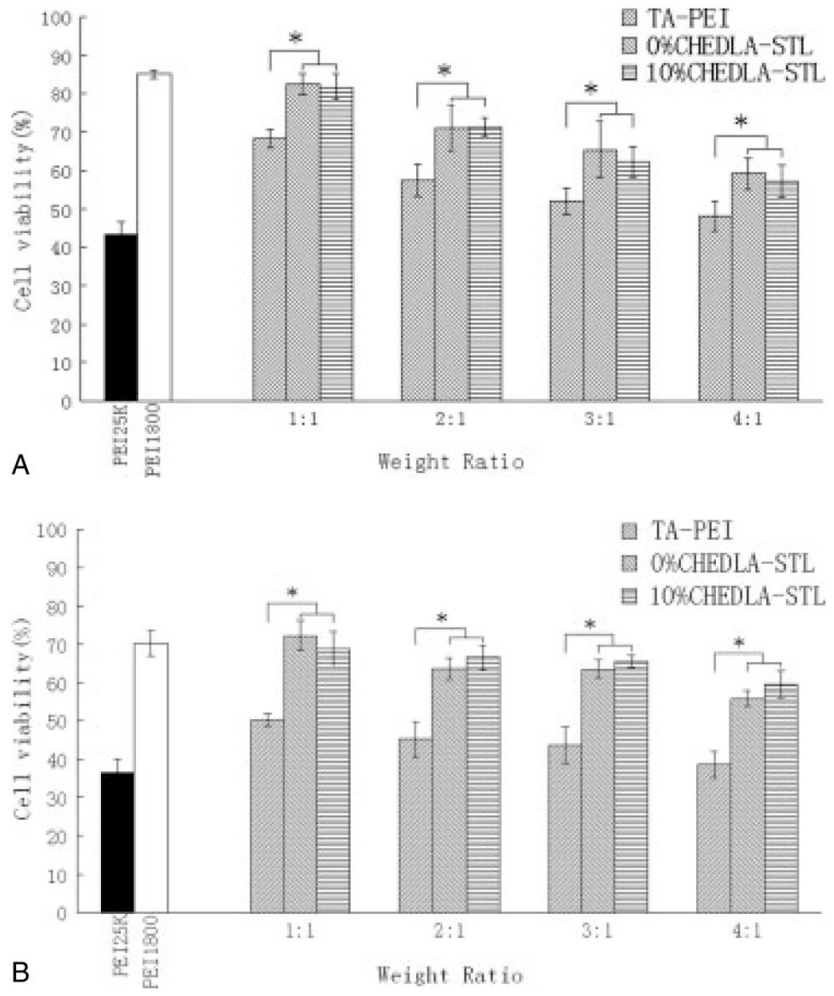

Figure 7.

MTT assay for cytotoxicities of TA-PEI/pDNA, STL/pDNA, PE 25K/pDNA and PEI 1800/ pDNA complexes in HEK 293 (A) and HepG2 (B) cells. PEI 25K and PEI 1800/pDNA complexes were prepared at a weight ratio of $1.3: 1$ and 5.3:1, respectively. The TA-PEI/ pDNA and STL/pDNA complexes were prepared at 1:1, 2:1, 3:1 and 4:1 (TA-PEI/pDNA, w/w). The STLs with or without CHEDLA were investigated simultaneously. The amount of pDNA was fixed at $0.2 \mu \mathrm{g} /$ well. The data represent the mean $\pm \mathrm{SD}$ of three experiments. *Statistically significant difference $(p<0.05)$ 


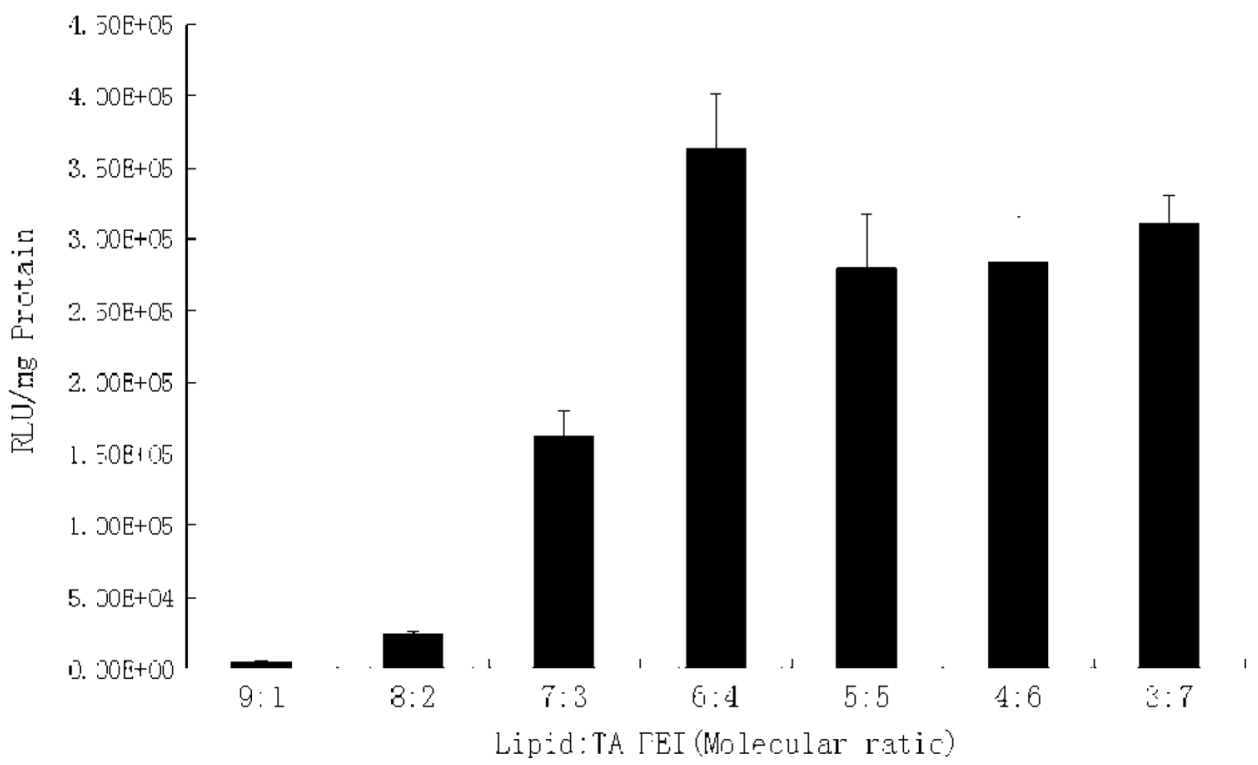

Figure 8.

Comparison of transfection efficiency of STL composed of phospholipid and TA-PEI at the indicated molar ratio. HepG 2 cells were incubated with STL complex containing $2 \mu \mathrm{g}$ of pDNA at a weight ratio of 3:1 (TA-PEI:pDNA) for $4 \mathrm{~h}$. At $48 \mathrm{~h}$ after transfection of HepG2 cells, luciferase expression was determined. The data represent the mean $\pm \mathrm{SD}$ of three experiments. ${ }^{*} p<0.05$ 


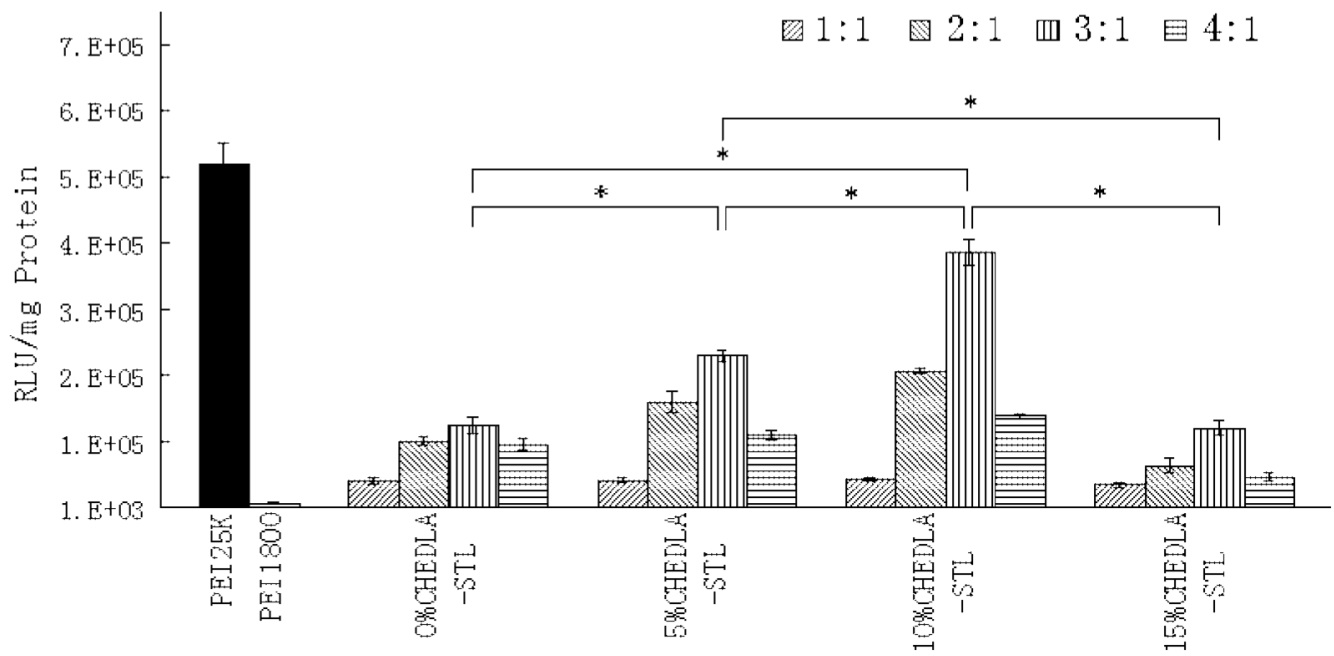

Figure 9.

Optimization of STL-mediated transfection when the concentration of CHEDLA or TAPEI/ pDNA ratio in STL was varied. STL with 0\%, 5\%, 10\% and 15\% CHEDLA were complexed with $2 \mu \mathrm{g}$ of pDNA at various weight ratios. At $48 \mathrm{~h}$ after transfection of HepG2 cells with these complexes, luciferase expression was determined. PEI 25K and PEI 1800/ pDNA complexes were prepared at a weight ratio of 1.33 and 5.3 as control, respectively. The data represent the mean $\pm \mathrm{SD}$ of three experiments. ${ }^{*} p<0.05$ 


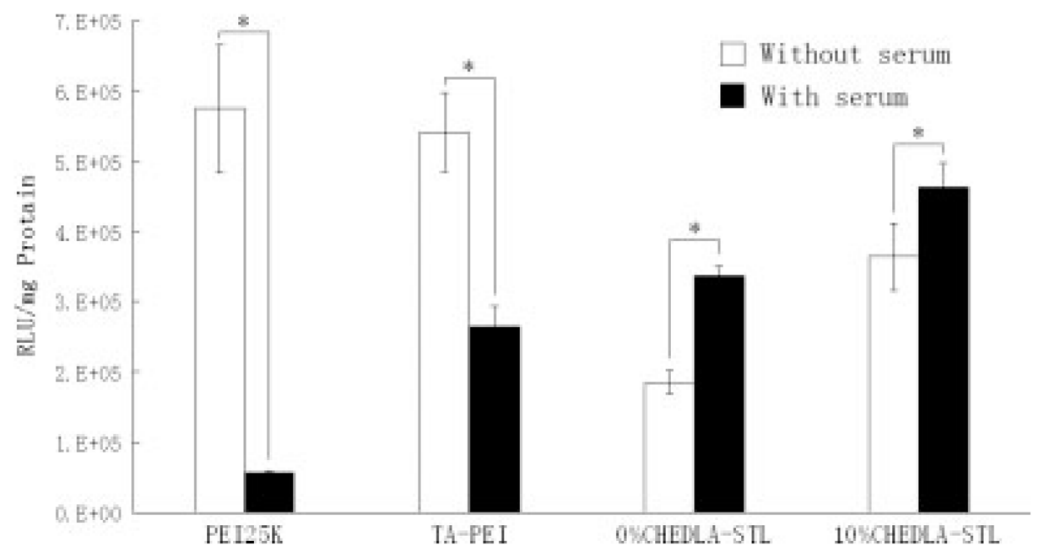

Figure 10.

Effect of serum on the transfection efficiency by PEI 25K, TA-PEI, STL complexes in vitro. PEI 25K, TA-PEI and STL/pDNA complexes were prepared at a weight ratio of 1.33, 3 and 3 , respectively, which complexed with $2 \mu \mathrm{g}$ of pDNA. HepG2 cells were incubated with complexes for $4 \mathrm{~h}$ at $37{ }^{\circ} \mathrm{C}$ in the presence or absence of $10 \%$ serum. At $48 \mathrm{~h}$ after transfection, the cells were solubilized and luciferase activity was determined in accordance with the manufacturer's suggested protocol. The data represent the mean \pm SD of three experiments. ${ }^{*} p<0.05$ 


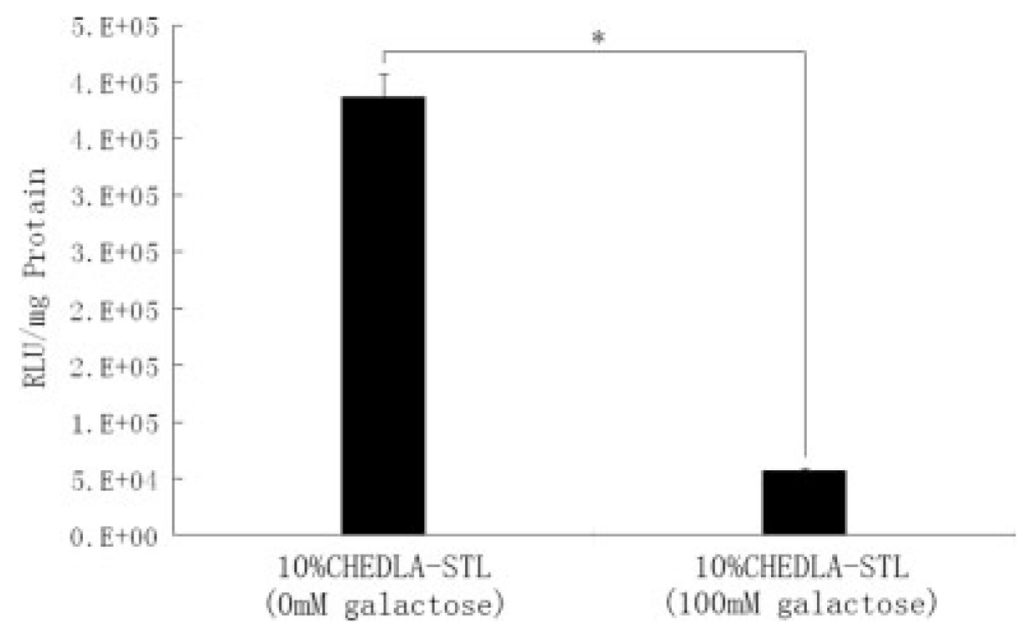

Figure 11.

Competition assay of STL/pDNA complexes prepared at a weight ratio of 3:1 (TAPEI:pDNA) by adding galactose $(100 \mathrm{mM})$ to compete with the galactase functional group in STL for ASGP-R sites. The data represent the mean \pm SD of three experiments. ${ }^{*} p<0.05$ 


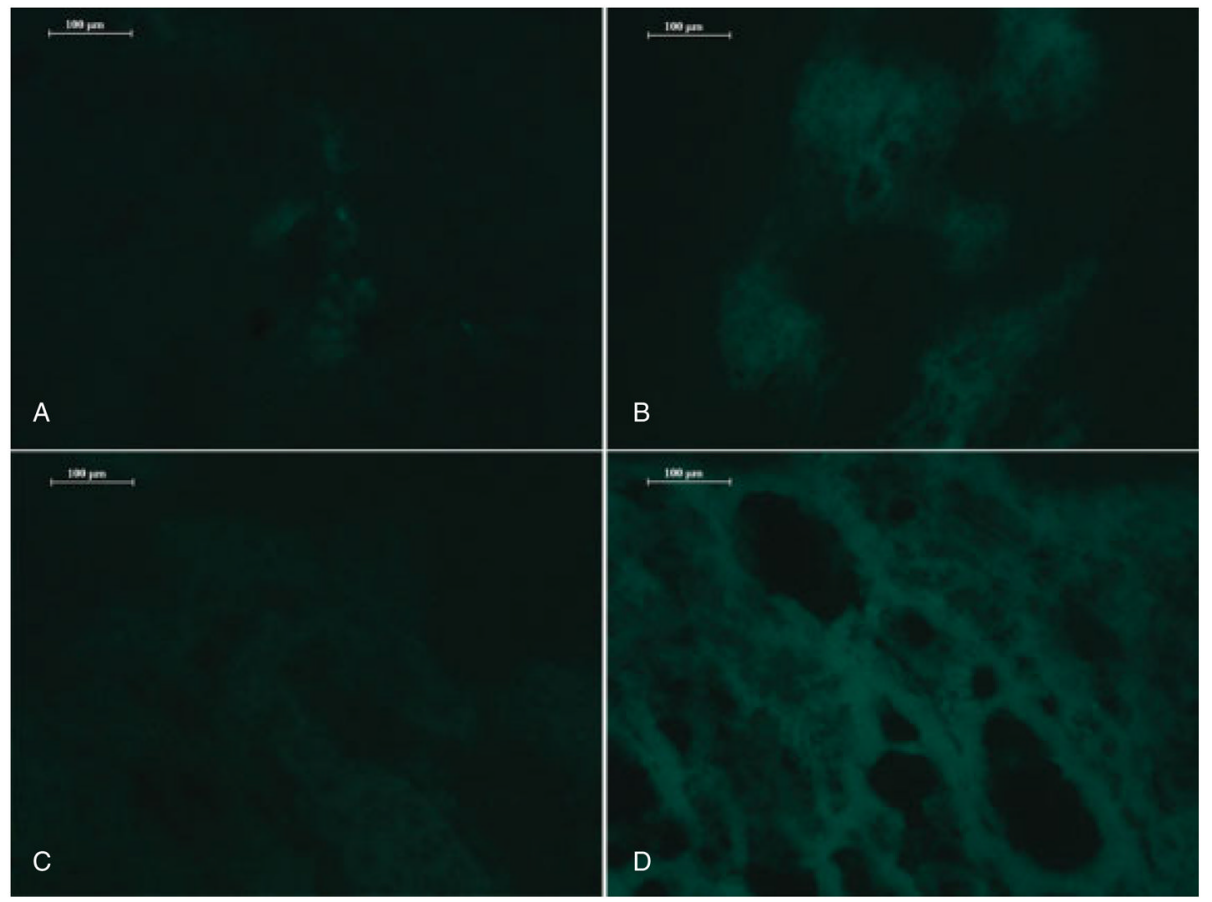

Figure 12.

The GFP expression was mediated by PEI 25K (A), PEI 1800-TA (B), 0\% CHEDLA STL (C) and $10 \%$ CHEDLA STL (D) in the liver after injection via portal vein. Scale bar $=100$ $\mu \mathrm{m}$ 

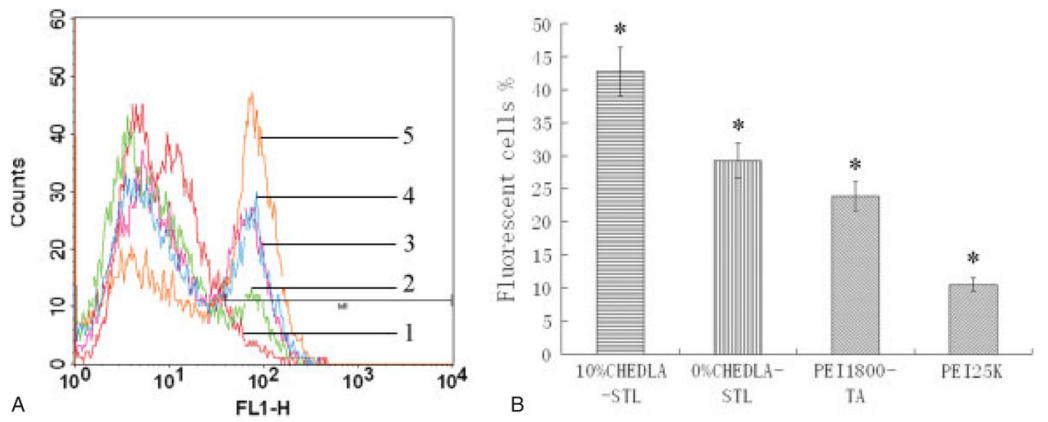

Figure 13.

Cell transfection in vivo with all four complexes was quantified by flow cytometry. (A) Flow cytometry data (the number of fluorescent cells and fluorescence intensity on the EGFP channel) for liver. 1: negative control; 2: fluorescence of cells treated with PEI 25K complexes; 3: fluorescence of cells treated with PEI 1800-TA complexes; 4: fluorescence of cells treated with 0\% CHEDLA STL complexes; 5: fluorescence of cells treated with 10\% CHEDLA STL complexes. (B) The average percentage of EGFP positive cells in liver treated with PEI 25K, PEI 1800-TA, 0\% CHEDLA STL and 10\% CHEDLA STL, respectively. The data represent the mean $\pm \mathrm{SD}$ of at least three experiments 